\title{
Normal Hearing after Trauma with Completely Ectopic Incus - How Possible?
}

\author{
Y.H. Zou H.Z. Liu S.M. Yang \\ Department of Otolaryngology - Head and Neck, Division of Surgery, Chinese PLA General Hospital, Beijing, China
}

\author{
Key Words \\ Incus · Traumatic dislocation · Hearing
}

\begin{abstract}
Objectives: To report the rare case of a patient with complete incus dislocation after trauma showing normal hearing. Methodology: Physical examination, audiometry, CT of temporal bone, and detection during operation. Results: The incus had become remotely located in the mastoid cavity, but the patient showed normal hearing because fibrous connections had preserved bony continuity. Conclusion: This case demonstrates that disruption of the ossicular chain does not always require ossicular reconstruction.
\end{abstract}

Copyright $\odot 2012$ S. Karger AG, Basel

\section{Introduction}

Proper alignment of the malleus, incus, and stapes, forming an integrated ossicular chain in the middle ear, is fundamental to normal hearing. Any breach of continuity produces conductive deafness. Traumatic dislocation of an ossicle typically leads to deafness on this basis and can only be reversed through reconstruction.

Herein, we report the rare and unexpected case, unparalleled in the literature, of a patient with normal hearing despite complete traumatic dislocation of the incus. The incus had become remotely located in the mastoid cavity during a traffic accident, but because fibrous connections had preserved bony continuity, there was no loss of hear- ing. This consequently demonstrates that disruption of the ossicular chain does not always require reconstruction.

This study was approved by the IRB Committee of the Chinese PLA General Hospital, and the patient has provided informed consent.

\section{Case Report}

The patient, a 20-year-old female, was hospitalized chiefly for right-sided facial paralysis following a traffic accident 2 months earlier. The facial paralysis was not discovered immediately, since she was initially comatose for 3 days. Once conscious, however, she also experienced occasional lapses of hearing in the right ear. One month after the accident, both air and bone conduction thresholds were normal by pure tone audiometry. She was ultimately transferred to our care for her unresolved facial paralysis.

Preoperative assessment revealed a normal external auditory canal, intact tympanic membrane, normal pure tone hearing threshold of the right ear from $250 \mathrm{~Hz}$ to $4 \mathrm{kHz}$ (fig. 1a), and a peripheral facial paralysis [grade V by House-Brackmann (HB) criteria] indicative of injury between the geniculate ganglion and stapedius branch. Temporal bone CT showed the ectopic ossicle within the mastoid cavity (fig. 1b) and a fracture line without bony dislocation. Magnetic resonance imaging of the brain disclosed no abnormalities.

Our patient underwent an endoscopically facilitated facial nerve decompression via mastoid approach. During this procedure, the incus was found far from its normal location, within the mastoid cavity (fig. 1c). Nevertheless, continuity of the ossicular chain had been maintained by smooth fibrous interconnections of the stapedic head, tympanic membrane, and malleus handle. A segment of facial nerve within the tympanic cavity was exposed and swollen (fig. 1d). Two months postoperatively, the patient's facial paralysis showed visible improvement (HB grade II-III).

\section{KARGER}

Fax +4161306 1234

E-Mail karger@karger.ch

www.karger.com (c) 2012 S. Karger AG, Basel

0301-1569/12/0745-0278\$38.00/0

Accessible online at:

www.karger.com/orl
Dr. S.M. Yang

Department of Otolaryngology - Head and Neck

Division of Surgery, Chinese PLA General Hospital

Beijing 100853 (China)

E-Mail yangsm301@263.net 

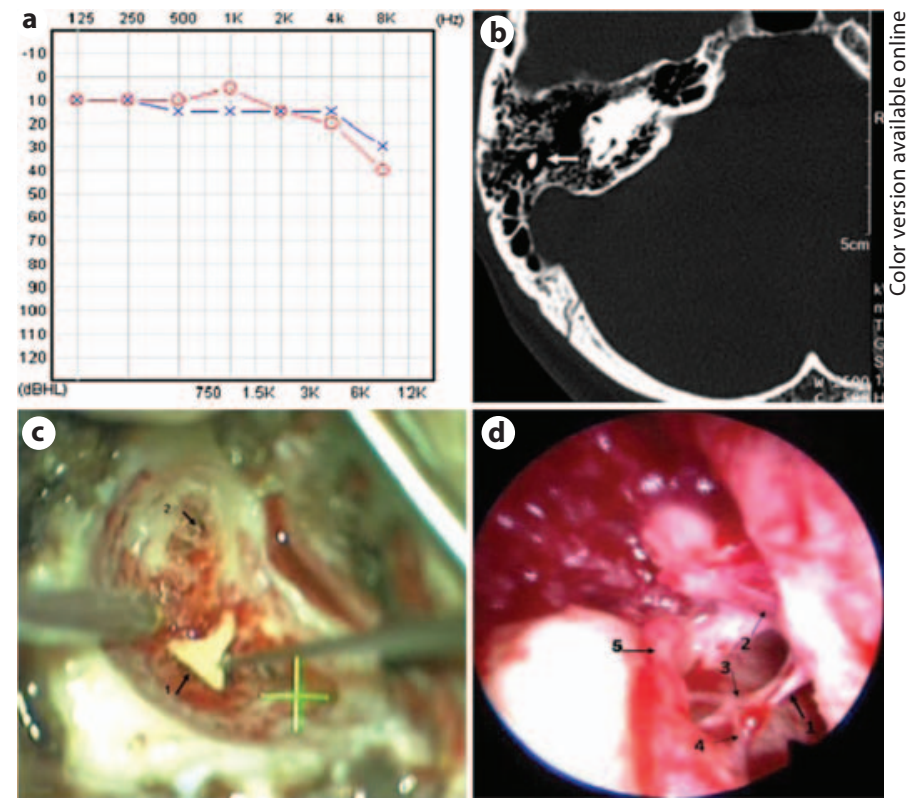

Fig. 1. Ectopic incus with normal hearing. a Preoperative pure tone audiogram: $0.25-4 \mathrm{kHz}$ normal hearing threshold. b Preoperative temporal bone CT showing ossicle in the mastoid cavity (arrow). c Ectopic incus in mastoid cavity. 1 = Intact ectopic incus; 2 tympanic antrum (the cross is from the microscope). $d$ Endoscopic image during surgery. 1 = Smooth fibers connecting the stapedic head, tympanic membrane, and malleus handle; $2=$ malleus handle; 3 = stapedic head; 4 = stapedic tendon; 5 = facial nerve.

\section{Discussion}

By all accounts, this patient should have suffered hearing loss with such decisive interruption of the ossicular chain. The fact that there were more significant injuries (coma, facial paralysis) to be dealt with early on and that hearing was normal on the opposite side undoubtedly hampered detection of the right-sided hearing deficit. One month later, pure tone audiometry elicited normal hearing on the right side, reflecting the fibrous connections that had formed and restored continuity of the ossicular chain. If facial nerve decompression had not been performed, the specified middle ear changes could easily have been overlooked.

Clinically, traumatic ossicular dislocation and temporal bone fracture concur often. The incidence is $30 \%$ according to Hollinger et al. [1], while a lower incidence (no exact number found) of simultaneous facial nerve paralysis is reported. Incus dislocation is the most common ossicular dislocation, with an incidence up to $63 \%$ [1-3]. Instances have been reported where the incus was repositioned into either external auditory canal or tympanic antrum, with varying degrees of hearing loss [4-6]. Holzapfel et al. [5] even cited a case where the incus had migrated into the external auditory canal while it was still connected with the stapes, so hearing was normal. In our patient, the incus was completely ectopic, being located within the mastoid cavity, far away from the tympanic antrum (fig. 1c). However, hearing was preserved by virtue of fibrous connections that maintained ossicular continuity, connecting the stapedic head, tympanic membrane, and malleus handle. Cases of this nature are remarkably rare but do underscore that not all traumarelated ossicular disruptions require surgical repair.

\section{Acknowledgements}

Grants from the National Basic Research Program of China (973 Program; No. 2012CB967900, 2011CBA01000) to S.M.Y. and the National Natural Science Foundation of China (NSFC; No. 31140047) to Y.H.Z. were received.

\section{Disclosure Statement}

The authors have no conflicts of interest.

\section{References}

1 Hollinger A, Christe A, Thali MJ, Kneubuehl BP, Oesterhelweg L, Ross S, Spendlove D, Bolliger SA: Incidence of auditory ossicle luxation and petrous bone fractures detected in post-mortem multislice computed tomography (MSCT). Forensic Sci Int 2009; 183:60-66.

-2 Yetiser S, Hidir Y, Birkent H, Satar B, Durmaz A: Traumatic ossicular dislocations: etiology and management. Am J Otolaryngol 2008; 29:31-36.
-3 Basson OJ, van Lierop AC: Conductive hearing loss after head trauma: review of ossicular pathology, management and outcomes. J Laryngol Otol 2009;123:177-181.

4 Tsai YT, Chan KC: Traumatic incus dislocation into the external auditory canal. Otolaryngol Head Neck Surg 2009;141:786-787.
5 Holzapfel AR, Chang CY, Pereira KD: Ossicular chain dislocation with normal hearing. Ear Nose Throat J 2005;84:351-353.

-6 Saito T, Kono Y, Fukuoka Y, Yamamoto H, Saito H: Dislocation of the incus into the external auditory canal after mountain-biking accident. ORL J Otorhinolaryngol Relat Spec 2001;63:102-105. 